\title{
Research Report on Comparison of the Internet Copyright in Colleges and Universities in both the US and China
}

\author{
Jing LOU \\ School of Education Administration, Guizhou University of Finance and Economics, Guiyang, China
}

\begin{abstract}
With the development of global Internet technology, Internet piracy on campus has became a problem just waiting to emerge. This paper depend on the project of "Internet piracy survey on campus" witch carried out by Peking University, though compare the questionnaires data from china and America, share the University students in china behavior and attitudes toward Internet piracy. Based on this findings, we discuss how to draw up relevance police on campus, develop some possible technology and management method to guidance the justified uses of digital resource on campus.
\end{abstract}

KEYWORD: Internet Piracy on campus; digital resource; Comparison research

\section{PUTTING FORWARD THE ISSUE}

In recent years, the issue of Internet Copyright protection has been becoming a topmost important factor affecting the informatization construction in colleges and universities with the development of informatization of higher education, the construction and the increasingly wide application of the digital library, the distance education system and the education management information system, and more and more frequent use of the digital information resources. In the U.S, this issue is standing at the topmost list. Among all the network users in the U.S, the group of college and university students is the biggest network user next to the business circle. Furthermore, because the management environment in colleges and universities is in a comparatively loose status, and the consciousness of the students for protecting the intellectual properties is relatively weak, piracy frequently happens in campuses and it is a headache to fight against. In the history of the US' intellectual copyright, the event that the US Disc Industrial Association brought several sues directly against college and university students has attracted attention from all circles in the US, and set an alarm for the issue of the Internet Copyright protection in college and university campuses worldwide.

\section{SURVEY AND RESEARCH PROCEDURES}

The survey on the Internet Copyright Protection in Colleges and Universities conducted by the
Education Technology Department, Education College of Beijing University is one of the subsubjects of the key subject - International Comparison and Research on Informatization of Higher Education for the " $10^{\text {th }}$ Five" Plan for National Education Science. It commenced at 0:00, December $1^{\text {st }}, 2012$, and finished at 0:00, December $31^{\text {st }}, 2012$. The network questionnaire method was adopted for this survey mainly targeting at the campus network users among college and university students. 1183 students filled out the questionnaire forms with 949 copies of effective questionnaire from 107 colleges and universities in China.

\subsection{Design of the questionnaire}

The questionnaire was slightly adapted according to the real situations in China, and it was adopted as the questionnaire for the survey on the Internet Copyrightin the colleges and universities in China. It was a comprehensive questionnaire in form. Electronic questionnaire form was used for the survey as it is convenient for filling out. Immediately after a student hands over a filled questionnaire, he or she can see the statistical result and his or her comments (for the open questions in the questionnaire form), thus will help exchange views and opinions on the issue of Internet Copyright between students.

\subsection{Questionnaire distribution}

The network survey system of the Education Technology Department, Education College of 
Beijing University was used for this network questionnaire survey. Letters of invitation were issued on the BBS of the various colleges and universities, thus invited the students to be inquired to fill out the questionnaire form. Usually, the letters of invitation were sent at midday and nightfall, the rush hours for networks. During the survey period (30 days), the letters of invitation were sent 2-3 times/day. Generally, the letters of invitation were sent to 3 forums on the BBS with the most on-line students. Considering the sexes of the students to be inquired (less women are interested technical forums than men), the letters of invitation were also sent to various forums.

\subsection{Survey data collecting and processing}

It should be sure that all the IP addresses for filling out the questionnaire forms be from the IP addresses within the various colleges and universities. For this purpose, we consulted the IP address stack and the "who is" server in the Asia-Pacific region for confirming the IP addresses participating in the survey, thus ensured that all the IP addresses were in the colleges and universities in China. Even if the IP address was in a college or university, should the filled questionnaire form be handed over again with 10 minutes, the second handed over questionnaire form was regarded as invalid.

\section{COMPARISON OF THE SURVEYS}

\subsection{The existing situations of the network piracy issues}

\subsubsection{Comparison of piracies of audio-video products through networks}

As it can be seen from the data shown in Fig. 1, the college and university students in the US who have exchanged music files through Internet download or by BT account for about $69 \%$, in comparison, the percentage in China is higher and it is $75.2 \%$. Comparing with the music download, less students in the US have conducted film download and it accounts for only $26 \%$, but the percentage in China is greatly higher than that in China and reaches $77.2 \%$. For charges paid, as it is shown in Fig. 2, the ratio of students who have paid for the download in both countries is low. For music download, over $90 \%$ of the students who have downloaded music files have never paid for the download in both the US and China.

\subsubsection{Comparison of piracies through network for Unlicensed Commercial Software}

As for the piracy issue for Unlicensed Commercial Software through networks, as it is shown in Fig. 1, $77 \%$ of the college and university students in the US said that they had downloaded through network or exchanged commercial software by P2P. In China, it is somewhat better $(55.3 \%)$, but the percentage of the students who have paid for the download or exchange is lower, and account for only $1.2 \%$. It is better in the US, this percentage reaches $11 \%$ (see Fig. 2). Generally speaking, the percentage of students have paid for the download or exchange when downloading commercial software is low in both the US and China.

Therefore, from the above data, it is very common that the piracy of audio-video products such as music and film files and the Unlicensed Commercial Software by students through campus networks is wildly spread, and this phenomenon is more serious in China than in the US. The campus piracy through networks should be solved, and the Chinese colleges and universities should realize this issue and pay sufficient attention to it.

\subsection{The awareness and attitudes towards Internet Copyrightprotection}

\subsubsection{Comparison of the attitudes towards the issue of network piracy}

As it is shown in Fig. 1, for the issue of music, film and software piracy, about $20 \%$ of the college and university students in the US admitted that the would download in order to save money. In comparison, it is more serious in China, about $78 \%$ of the college and university students said that they would download in order to save money even if they knew the downloaded music, films and software were piracies.

\subsubsection{Comparison of the most concerned problems} faced when using piracy software

As it is shown in Fig. 3, in the colleges and universities in the US, when using Unlicensed Commercial Software, only $25 \%$ of the students concern most about the violation of laws or the university policies, and $44 \%$ care most about computer viruses, quality or perfection of functions in or of the software. While in China, $69.2 \%$ of the college and university students care most about computer viruses, quality or perfection of functions in or of the software, only 5\% worry about the violation of the copyright law or the relevant regulations of the college or university.

\subsubsection{Comparison of the views and opinions for downloading or exchanging files without payment}

As it can be seen from the data in Fig. 4, on the issue of file download or exchange without payment, most of the college and university students in China don't occupy the basic awareness, more than half (54.7\%) hold the view that "it is difficult to tell whether the activity to download or exchange pay-files is right or wrong", and it is one time higher than that in the US 
(27\% of the college and university students in the US). In China, only $15.3 \%$ of the students consider that this activity is totally wrong, and it is less than that in the US $(23 \%)$.

\subsubsection{Comparison in judging the piracy activity}

As it can be seen from the data in Fig. 5, the college and university students in both the US and China consider that the piracy activity is rational at some extent. One of the main reasons for software piracy is that the price of the original software is higher comparing with its cost. In both countries, about $80 \%$ of the students agree with this point of view, furthermore, nearly half of the students hold the view that the commercial profit in the software industry is high and its development will not be hampered if the unlicensed software is only used by a few people.

\subsubsection{Comparison in the awareness for intellectual copyright protection}

Currently, the most concerned is the situation of the network piracy in campuses, but fortunately, the students are now correctly realizing the issue of intellectual copyright protection less or more. It can be seen from the responses to the issues of intellectual copyright protection from the college and university students in both the US and America listed in Table 2, most of the students in China (about 95\%) hold that the standpoints that "the software developers should deserve the necessary returns for their intellectual work" and "the protection of intellectual copyright is helpful to the further investment and development on or of the software industry" are correct. More than $80 \%$ of the students in the US agree with this standpoint. In addition, more than half of the students in both countries favor the issue "the protection of intellectual copyright should be strengthened with regard to the software download through campus networks".

\subsection{Management of the protection of campus networks}

\subsubsection{Comparison of the education work for copyright protection conducted by the colleges and universities}

It can be seen from the data in Table 3, In the colleges and universities in China, only $17.1 \%$ of the teachers will warn their students not to copy and disseminate the various printed materials in class, also in the US, only $22.2 \%$ of the teachers will dissuade their students from piracy of the printed materials. In contrast, only $12.1 \%$ and $3.9 \%$ of the teachers in China will admonish their students not to conduct piracy. In these two aspects, the teachers in the US have done relatively better in the education to their students, about $20 \%$ of the teachers will dissuade their students from network piracy. Generally speaking, the teachers in both countries have not done enough in the copyright education to their students. Another problem present in the education for copyright protection in colleges and universities is that the teachers themselves don't have sufficient knowledge in the protection of network copyright.

\subsubsection{Comparison of formulation and propaganda of the polices for copyright protection}

Generally speaking, the colleges and universities in the US are actively reporting the problems resulted from the licensed information download through campus networks by students. As it can be seen from the data listed in Table 4, although most colleges and universities in the US have formulated the relevant polices and regulations with regard to the copyright protection, only $28 \%$ of the students know the polices and regulations. It is even worse in China, only $11 \%$ of the students know that their college or university has formulated the relevant polices for the licensed software. In both countries, only small part of the students (about 10\%) hold that these polices are valid. It seems that there is a long way for the colleges and universities in both countries to go for the policy propaganda.

\section{POLICY SUGGESTIONS}

\subsection{Paying attention to the legislation of the intellectual copyright of the information of the education networks, and improving the consciousness for the protection of the network intellectual copyright}

In the process of deepening the development of informatization, the construction of the information legislation is an important means of safeguard. China commenced this work at a relatively late stage. These provisions and regulations have brought certain positive effects to the ordering and legislation for the environment of the information of the education software, but under the situation that the imformatization process in the colleges and universities is developing rapidly, some issues with regard to the violation of the intellectual copyright have been resulted from new technologies. Both the legislation and the judicial practice for the protection of the intellectual copyright have to be further strengthened.

\subsection{Management measures for strengthening the copyright of the campus networks}

\subsubsection{To be registered at the related copyright management institution}

As an in-line service provider (ISP), the college or university should bear certain legal liabilities within 
certain scope for the network piracy activities conducted by its own personnel. Therefore, as it is suggested in the Case of the Copyright for the DigitMillennium, for the college or university to fulfill its liabilities and obligations as an ISP, it should apply for registration at the related copyright management institution in time, in this case, it will receive the documents required and enjoy the protection polices by the copyright management institution.

\subsubsection{To set up a special department and organize personnel to manage the copyright protection}

The college or university can set up a special department and organize personnel to manage its copyright protection, furthermore, it can engage specialists on laws to deal with the issues relating to the copyright. On one hand, the college or university can contact the copyright management institution in time, and receive the information relating to the copyright protection or violation, on the other hand, it can carry out propagandas with regard to the Internet Copyright to the students.

\subsection{To integrate technologies with managerial measures to protect the copyright of the campus network effectively}

4.3.1 To strengthen the security management measures of the campus networks to find out the invasion from the computers outside the campus timely, and to prevent the computers in the campus from being used as shared servers for the various P2P software.

4.3.2 To improve the managerial technologies for the massive data exchange flow in the campus. Although the college or university will not supervise the contents of the data exchanged through the campus network, it will supervise and control the data flow of the computers through the campus network appropriately.

4.3.3 To perfect the managerial technologies for the accounts of the campus emails and FTP. More than $40 \%$ of the colleges and universities in the US have stipulated a rule that the appendix attached to an email should not exceed a limited volume (1.5 M to $4 \mathrm{M}$ ) to prevent the students against transferring piracy resources through emails. When a student wants to apply for a FTP, he or she has to apply for registration.

\subsection{To make reasonable use of the digital information resources of the campus network}

As an education institution, the college or university acts as both the creator of academic exchangers and user of academic achievements. On one hand, the colleges and universities should follow the stipulations in the copyright laws, and conduct their educational and academic activities as per the copyright laws, on the other hand, they should balance the various benefits involved in the respect of the academic researches and academic freedom, non-interference in education and scientific research, and protection of the use of digital information resources in the education circle as per the copyright laws.

4.4.1 On the condition that the lawful rights and interests of the works under the copyright protection are well protected, the education institutions such as colleges and universities enjoy the right to obtain the digital information resources for teaching, learning, academic researches and individual studies through reliable ways.

4.4.2 As an information user as well as an information provider, the college's or university's activities on the Internet will have direct influences on the use of the information under copyright protection by its various departments and individuals. In some fields, especially involved in the information materials relating to electronics and multi-media, they users don't quite understand the copyright laws and the rules for reasonable use, in this case, it is necessary for the college or university to provide common explanations and interpretations to the various departments and individuals according to the existing laws and rules.

4.4.3 While using the digital information resources on the networks, the colleges and universities bear the responsibilities and liabilities for respecting the copyright and the rights of the copyright holders. The colleges and universities should conduct education on the laws relating to the intellectual copyright to the departments and the users of the campus networks under their administration, manage and control the digital information resources on the campus networks technologically, and eliminate the activities violating the network copyright. As a result, the balance between the intellectual copyright and "reasonable use" can be maintained.

\section{REFERENCES}

[1] Zhao.G (2003)comparison of Campus Computing on China United States and Hong Kong colleges: ACCS Report.

[2] Xiao Y.(2001) Using Internet Educational Information Resources in Reason Retrieved August 3, 2004, from China Education and Research Network Web.

[3] Yang.Q.(2003) Document Exchange has been prohibited in US Colleges. 